\title{
BEDEN EĞiTiMI VE SPOR YÜKSEKOKULLARINDA ÖRGÜT KÜLTÜRÜ
}

\author{
Pervin BíLiR ${ }^{1} \quad$ Ünal AY ${ }^{2} \quad$ Tuğba ÇELiK GÜRBÜZ ${ }^{1}$
}

Geliş Tarihi: 05.12 .2003

Kabul Tarihi: 29.01.2004

\section{ÖZET}

Günümüzde, yaşam kalitesini olumlu veya olumsuz yönde etkileyen faktörlerin gerisinde, ilişkide olduğumuz örgütlerin performans düzeyi vardır. Yirminci yüzyıldan itibaren bireylerin değişik tür ve amaçtaki örgütlere bağımlılı̆ı artmaktadır. Günümüzden elli yıl önce yaşayan bir bireyin günlük yaşamı, bugünün bireyi ile karşılaştırılığında, günümüz bireyi daha çok sayıda ve farklı amaçtaki örgütlerle ilişki halindedir.

Örgütler, insanların değişik intiyaçlarının giderilmesi ve amaçlarının gerçekleştirilmesi için vardır. Genelde misyon olarak da bilinen örgütün varolma nedeni, bütün örgütler için, insanın yaşam kalitesini ve refahını artırmaktır denilebilir. Ancak araştırma, inceleme ve gözlemlerin de ortaya koyduğu gibi, insan ihtiyaçlarını karşılama ve sorunlarını çözme açısından örgütlerin hepsi yeterli performansı gösterememektedir. Örgütsel performans düzeyini belirleyen çok sayıda unsur olmasına rağmen, özellikle 1980'li yıllardan itibaren, örgüt kültürü kavramı üzerinde durulmaya başlanmıştır. Girdisi ve çıktısı insan olan eğitim örgütlerinde kültür kavramını incelemek yaşamsal bir önem taşımaktadır. Eğitim örgütlerinde herkesin ortak değer ve inançlar çerçevesinde iş görebilmesi yani, ortak bir güçlü kültürün yaratılabilmesi, amaçların gerçekleştirilmesinde önemli rol oynamaktadır.

Bu araştırmanın amacı, Beden Eğitimi ve Spor Yüksekokullarının örgütsel kültürünü incelemek ve anlamaktır. Araştırmanın evrenini, ülkemizin Güneydoğu Anadolu Bölgesi'nde yer alan Üniversitelerin bünyesinde bulunan Beden Eğitimi ve Spor Yüksekokulları çalışanları oluşturmaktadır. Bu yüksekokullarda çalışan yönetici, akademik ve idari kadroda çalışanlar arasından tesadüfü olarak seçilmiş 94 kişi, araştırmanın örneklem grubunu oluşturmuştur.

Araştırma verilerinin istatistik analizleri SPSS paket programında yapılmıştır. İstatistik analiz olarak; betimsel ve yordamsal istatistik kullanıımıştır. Farklıııklar; "T testi" ile saptanmıştır.

Araştırma sonuçlarına göre, üzerinde çalışılan yüksekokulların zayıf bir örgüt kültürüne sahip oldukları belirlenmiş olup, örgüt kültürü ile ilgili temel sayıltı ve uygulamaların bazılarının algılamalarında, cinsiyet değişkenine göre anlamlı farklılık bulunduğu ( $p<0.05)$ saptanmıştır.

Anahtar kelimeler: Beden Eğitimi ve Spor Yüksekokulu, Örgüt Kültürü

\section{A STUDY OF ORGANIZATIONAL CULTURE IN PHYSICAL EDUCATION AND SPORTS SCHOOLS}

\section{ABSTRACT}

There is a strong relationship between living standards and effectiveness of all types of organizations. Because, in terms of achieving an increase in living standards of people, there is a need to increase organizations' performance.

In general, all organizations exist to meet variety of needs of people. While some organizations are successful to meet and satisfy the needs of its stakeholders, some are not so successful. Though the determinants of organizational performance are many and complex, several studies indicate that organizational culture is one of the major factor in distinguishing successful and not so successful organizations.

The purpose of this study is to examine and develop an understanding of the culture of Physical education and Sport schools. The population of the study consists of those individuals employed in the Physical Education and Sport schools. These schools are located in the southeast region of Turkey. The sample is made up of 94 individuals who were drawn from the population randomly.

SPSS software is used in order to analyze data obtained from the study participants. Both descriptive an inferential statistical procedures (arithmetic means and standard deviations, and t-test) are employed to analyze the data.

The findings show that Physical education and Sport Schools' cultures may be characterized as weak culture. Assumptions and practices of these schools' cultures, as perceived by the participants, vary according to the school and the gender of the participants.

Key words: Organizational Culture, Physical Education and Sports School

\footnotetext{
${ }^{1}$ Çukurova Üniversitesi Beden Eğitimi ve Spor Yüksekokulu

${ }^{2}$ Çukurova Üniversitesi İktisadi ve İdari Bilimler Fakültesi
} 


\section{GíRiş}

Günümüzde, yaşam kalitesini olumlu veya olumsuz yönde etkileyen faktörlerin gerisinde, ilişkide olduğumuz örgütlerin performans düzeyi vardır. Yirminci yüzyıldan itibaren bireylerin değişik tür ve amaçtaki örgütlere bağımlılğı artmaktadır. Örgütler, insanların değişik intiyaçlarının giderilmesi ve amaçlarının gerçekleştirilmesi için vardır. Genelde misyon olarak da bilinen, örgütün varolma nedeni, bütün örgütler için, insanın yaşam kalitesini ve refahını artırmaktır denilebilir. Ancak araştırma, inceleme ve gözlemlerin de ortaya koyduğu gibi, insan ihtiyaçlarını karşılama ve sorunlarını çözme açısından örgütlerin hepsi yeterli performansı gösterememektedir. Örgütsel performans düzeyini belirleyen çok sayıda unsur olmasına rağmen, özellikle 1980'li yıllardan itibaren "örgüt kültürü" kavramı üzerinde durulmaya başlanmıştır.

Örgütsel yaşamın dinamikleri karmaşıktır. Bu karmaşıklığı anlamak için örgütsel kültürü anlamak gerekmektedir. Antropolojik çerçeveden bakıldığında bireysel ve toplu yaşam, ancak kültür temelinde bina edilerek açıklanabilir. Örgütsel açıdan da kültür benzer bir işlevi ve rolü üstlenmektedir (1).

Kültür, örgütte bir dizi işlevi yerine getirir, örgütün diğer örgütlerden farklı yönlerini belirtir, örgüt üyelerine kimlik duygusunu aktarır, çalışanların bir şeye bireysel çıkarlardan daha fazla bağlanmasını kolaylaştırır, sosyal sistemin dengesini güçlendirir ve sosyal bir yapıştırıcı rolü oynar, iş görenlerin tutum ve davranışlarını şekillendiren ve yönlendiren bir anlam-yaratıcı ve denetim mekanizması hizmeti görür (2).

Yüksek eğitim kurumları özellikle sadece öğrenci ve çalışanlarına değil toplumun geneline, sorunlarını nasıl çözeceğinin çerçevesini (kültürünü) belirleme yöntemini öğretme işini üstlenmiştir. Bir eğitim kurumundan söz edildiğinde genellikle yapısından ve programından söz edilir. Fakat bir okulun en önemli özelliği, onun yazılı olmayan norm çevresi ve beklentilerinden oluşan kültürüdür. Bazı örgütler ciddi, bazıları eğlenceli, bazılarında verimlilik, bazılarında ise, insan ilişkileri en önde gelir. Okullara baktığımızda, bu özelliklerin tümünü içeren örgütler olduğunu görürüz (3).

Okulun en önemli özelliği üzerinde çalışılan hammaddenin insan oluşudur. Bu nedenle birey boyutu kurum boyutundan daha duyarlı, informal yanı formal yanından daha ağır, etki alanı yetki alanından daha geniştir. Ayrıca okulun içinde ve dışında sosyal, politik ve ekonomik değerleri uzlaştırmak ve dengelemek durumundadır (4).

Beden Eğitimi ve Spor eğitimi, ülkemizde, 1982 yılına kadar, Gençlik ve Spor Akademileri ile Eğitim Enstitülerinin Beden Eğitimi ve Spor Bölümlerinde verilmekteydi. 2547 YÖK Kanunu ile birlikte 1982 yılında, Bakanlar Kurulu Kararıyla Gençlik ve Spor Akademileri, Eğitim Enstitülerinin Beden Eğitimi ve Spor Bölümleri ile birleştirilmiştir(5). YÖK kanununda yapılan bu değişiklikle, Beden Eğitimi ve Spor Bölümleri, Eğitim ve bazı Üniversitelerde Fen Edebiyat Fakültelerine bağlı birer bölüm olarak eğitimlerini sürdürmüşlerdir. Beden Eğitimi ve Spor Bölümleri, 1992 yılından itibaren birer, birer Bakanlar Kurulu Kararları ile, Üniversitelerde rektörlüğe bağlı yüksekokullar olarak, ayrı bir eğitim örgütü konumuna getirilmişlerdir. Bu yüksekokullar, beden eğitimi öğretmeni, antrenör ve spor yöneticisi yetiştirmektedirler. Kaliteli elemanların yetiştirilmesi, kaliteli bir örgüt sürecinden geçmeye bağlı olduğu düşüncesi herkes tarafından kabul görmektedir.

Üniversitelerin eğitim birimleri kültürün bir nesilden diğerine aktarılmasından özellikle sorumludurlar, çünkü misyonları bu şekilde tasarlanmıştır(6). Bu nedenle, bu kurumların kültürel özelliklerini anlamak ve tanımlamak gerekmektedir.

$\mathrm{Bu}$ araştırmada, örgütsel kültür, örgütsel kültürün öğelerinden olan, paylaşılan "Temel Sayıtılır" ve "Uygulamalar" ile açıklanmaya çalışılmıştır. Buna göre, Beden Eğitimi ve Spor Yüksekokullarında (BESYO) çalışan yönetici, akademik ve idari personelin insan ve onun içinde yaşadığı çevreyle ilgili paylaştıkları bazı temel sayıltılarla, söz konusu grupların algılarına dayalı olarak BESYO'lardaki bazı uygulamaların değerlendirilmesiyle, bu yüksekokullarda nasıl bir örgütsel kültürün oluştuğu saptanmaya çalışılmıştır.

Bu araştırmadaki temel sayıltılar; BESYO'larda görevli yönetici, akademik ve idari çalışanların "çevreyle ilişkiler", "gerçek", "insan", "insan eylemleri" ve "insan ilişkilerinin doğasıyla" ilgili olarak inançları ifade etmektedir. Örgütsel uygulamalarla ise; yüksekokul yönetimi, akademik ve idari çalışanlarla ilgili olarak okulun örgütsel, yönetsel, eğitsel, sosyal ortamında oluşan bazı durumlar ifade edilmektedir.

\section{Örgüt Kültürünün Tanımı} görülmektedir.

Bilim dünyasının bu kavrama yükledikleri anlama göre, bir çok örgütsel kültür tanımlarının yapıldığı

Schein, örgüt kültürünü, üç boyutta açıklamıştır (7):

1.Temel Sayıltılar: Örgüt üyelerinin, çevreyle ilişkiler, gerçek, insan eylemleri ve insan ilişkilerinin doğasıyla ilgili olarak paylaştıkları temel inançlar,

2. Temel Değerler: Örgüt üyelerinin, olay, durum, ve davranışları değerlendirmede, yargılamada benimsemiş oldukları ölçütler,

3. Artifaktlar: Daha çok kültürün gözle görülen yönünü oluşturmakta, teknoloji, üyeler tarafından sergilenen sanat-mitler, semboller, hikayeler, efsaneler ve görülebilen, işitilebilen davranış örüntülerinden oluşmaktadır. 
Schein(1985)'ın örgütsel kültürü açıklama yöntemi kullanılarak, okullarla ilgili bazı örgütsel kültür araştırmaları yapılmıştır(7). Plath(1987) bu yöntemin okullardaki örgüt kültürünü açıklamak için kullanıp kullanılamayacağını sınamak amacıyla bir araştırma yapmış ve bu yöntemin okulların örgütsel kültürünü açıklamak için de başarıyla kullanılabileceği sonucuna varmıştır (8). Dört Yüksekokulda örgütsel kültürün özelliklerini araştıran Kafka(1988), örgütsel kültürün açıklanmasında Schein'ın örgütsel kültürü açıklama yöntemini kullanmıştır (9).

Ülkemizde ise, Schein'ın örgütsel kültür ögelerine ilişkin ve açıklama yöntemini temel alan Şişman (1994), okullarda yaptığı araştırmasında elde ettiği sayısal verileri faktör analizi ile çözümlemiştir(10). Bu araştırma, Şişman'ın yaptığı temel sayıltılar ve uygulamalara ilişkin öğeler temel alınarak yapılmıştır.

Robbins(1988), Harwey ve Brown(1988) ise, örgütsel kültürlerin, bir takım yönetsel, örgütsel uygulamaların (örgütsel yapı, kontrol sistemleri, ödül-ceza sistemleri vb.) çözümlenmesiyle açıklanabileceğini ileri sürmüşlerdir $(11,12)$.

Malinowski (1948) kültürü, insan düşüncesi ve yarattığı eşyalardan, inanç ve törelerden; kısmen materyal kısmen insan, bazen de insanın iç dünyası ile ilişkili karmaşık bir enstrümandır. Bu enstrümanı kullanarak insanlar somut, spesifik problemlerini görmeye çalışmaktadırlar. Anayasa, hukuk ve diğer kurumlar da kültürün bir parçasıdır şeklinde tanımlamıştır (13).

Lessem (1990) ise, gelişme odaklı bir tanım sunmaktadır. Örgüt kültürü insanların tatmin olabilecekleri bir çerçeve (iklim) yaratmalı. Ancak böyle bir ortamda intiyaç duyulan ürün ve hizmetlerin üretimi, ürün ve hizmetin değeri ve kalitesi oluşabilir (14).

Örgüt kültürünü genel olarak tanımlamak gerekirse, örgüt kültürü; bir örgütte paylaşılan temel sayıltılar, değerler, semboller ve uygulamalardır.

\section{Örgütsel Kültürlerin Sınıflandırılması}

Literatüre bakıldığında örgütsel kültürler, araştırmacılar tarafından farklı şekillerde sınıflandırılmıştır.

Hofstede (1980), örgütlerdeki kültürün, ulusal kültürden etkilenmesi üzerine, yapmış olduğu araştırma sonuçlarına göre örgütsel kültürü şu özellikler şeklinde sınıflandırmıştır; Güç Mesafesi Özelliği, Belirsizlikten Kaçınma Özelliği, Bireycilik/Iş̧birliği Özelliği, Eril ve Dişil Özellikler (15). Handy'in (1981) kültür sınıflandırması da; Rol Kültürü, Görev Kültürü, Güç Kültürü, Birey Kültürü şeklindedir(16). Quinn and McGarth(1985), değişik bir yaklaşımla örgütsel kültürleri, Rasyonel, Gelişmeci, Uzlaşmacı ve Hiyerarşik kültürler olarak dört grupta sınıflandırmıştır(17). Kono(1992), örgüt kültürlerini; Canlı Kültür, Lider Eksenli Canlı Kültür, Bürokratik Kültür, Durağan Kültür, Güçlü Lider Eksenli Durağan Kültür olarak beş grupta sınıflandırmıştır(18). Cook ve Wallach, örgüt kültürlerini, Bürokratik, Yenilikçi, ve Destekleyici olarak üç sınıfta toplamıştır (19).

Berguist (1992), Üniversitelerde birbirinden farklı dört kültürden söz edilebileceğini ileri sürmektedir. Her kültürün kendine özgü geçmişi, bakış açısı ve değerler sistemi mevcuttur. Berquist bu dört kültüre ait özellikleri şöyle belirtmektedir (1):

1. Kolej Kültürü: Akademisyenlerin temsil ettiği bölüm veya alanın kurum içindeki anlamını öne çıkaran kültür tipidir. Bu kültürün değer verdiği eylemler arasında akademik araştırma, akademisyenlerin yönetimde söz sahibi olması başta gelmektedir.

2. Yönetim Kültürü: Bu kültür çerçevesinde tanımlanan bir kurumun temel işi özel bilgi, beceri ve tutumların öğrencilere etkili biçimde aktarılması vardır. Zira öğrenci bu bilgi, beceri, tutum olmaksızın sorumlu ve başarılı vatandaş olamaz.

3. Geliştirme Kültürü: Bu kültür, kurum üyelerinin, bireysel ve profesyonel gelişimine verdiği önem ile tanımlanmaktadır. Çeşitli program, proje ve faaliyetlerin amacı bireylerin gelişimine katkıda bulunmaktır.

4. Görüşmeci-Pazarlıkçı Kültür: Bu kültür, kurum kaynaklarının tahsisi ve yaratılan faydanın paylaşımında eşitliğe önem veren bir kültürdür. Üyeler arasında karşılıklı sorgulama ve çıkarların pazarlığının yapılmasına değer verilmektedir.

Örgütsel kültürleri, Deal ve Kennedy (1982), Peters ve Waterman (1987), güçlü ve zayıf kültürler olarak sınıflandırmışlardır $(20,21)$.

Şişman (1994), güçlü kültürlerin özelliklerini şu şekilde sıralamıştır (10):

1. İşörenlerin yaratıcılık ve başarı güdüleri teşvik edilir, mesleki gelişimi ve işindeki başarısı için yönetim tarafından her türlü destek ve yardım sağlanır. Örgütte yenilik ve değişmelerle gelenekler; otoriteyle özerklik arasında bir denge kurulur.

2.Görevin yerine getirilmesinde işgörenlere büyük ölçüde özerklik verilir, işgörenler yanlış yapmaktan korkmaz, görevleriyle ilgili konularda risk üstlenme konusunda teşvik edilir. Bu nedenle örgütün kuralları dışına çıkanlar bu kuralları bozan kişiler olarak değil,kendilerini riske atan kişiler olarak kabul edilir.

3.Örgüt üyeleri arasında yarışmayla işbirliği arasında iyi bir denge sağlanır. İşgörenler işleriyle ilgili konularda kendi aralarında bir yandan yarışmaya, diğer taraftan da karşılıklı yardımlaşma ve işbirliğine teşvik edilir. 
4. İşgörenler, yaptıkları işle ilgili konularda sorumluluk üstlenmeye teşvik edilir, isteklendirilir. İş görenler de yaptıkları işlerle ilgili konularda sorumluluk almaktan kaçınmaz.

5. Örgütte esnek bir yapı bulunur ve işgörenin kontrol edilmesine yakından denetim yerine, uzaktan denetim biçimi tercih edilir. Örgütte egemen olan kurallar, değişmez, katı kurallar değildir. Yazılı kurallardan çok yazılı olmayan kurallar önemli görülür.

6. Örgütte hoşgörü ortamı egemen olup, örgütsel çatışmalar karşılıklı anlayış içinde çözümlenir. Örgütte yapılan işlerle ilgili olarak işgörenlerin yapabileceği hatalar hoşgörü ile karşılanır ve örtbas edilir; şikayetler ise hoş karşılanmaz.

7. İşgörenin görevine olduğu kadar sosyal yaşantısına da ilgi gösterilir. İşgörenler arasında arkadaşlık ilişkileri teşvik edilir. Örgüt bir aile, köy, kulüp havası taşır. İşgörenler arasında karşılıklı güven ve dostluk bulunur.

8. İşgörenler arasında uyum ve ahenk bulunur. Örgütte yeni katılan üyeler, kısa bir süre içinde örgüte uyum sağlar ve örgütün diğer üyeleriyle kaynaşır.

9. Örgütte adil bir ödül-ceza sistemi bulunur; işgörene sağlanacak her türlü yardım,destek ve ödüllerde işgörenin performansı ve işindeki becerisi temel ölçütler olarak kabul edilir; imtiyazlı davranışlardan kaçınıır.

10. İş, örgüt üyeleri tarafından yaşamak için gerekli bir uğraş olarak görülür. Örgütte yapılan her iş, örgütün amaçlarının gerçekleşmesi ve örgütün başarısı içindir. Bu süreçte biçimsel kurallardan çok ulaşılan sonuçlar önemli görülür.

Bu araştırmada, örgütsel kültür sınıflandırılmasıyla ilgili sözettiğimiz sınıflandırma biçimlerinden güçlü ve zayıf örgütsel kültür sınıflandırması benimsenmiş olup, değerlendirmeler, yukarıda belirttiğimiz Şişman'ın (1994) güçlü kültürü tanımlama kriterleri gözönünde bulundurularak bulgular yorumlanmıştır.

\section{AMAÇ}

Bu araştırmanın amacı, Beden Eğitimi ve Spor Yüksekokullarında, yönetici, akademik ve idari personelin, temel sayıltıları ve örgütsel uygulamalara ilişkin algılarına bağlı olarak, yüksekokullarda nasıı bir örgüt kültürü oluşturulmuş olduğunu ortaya koymaktır. Bu nedenle araştırmamızda, şu sorulara yanıt aranmıştır:

1. Besyo'larda nasıl bir örgüt kültürü oluşturulmuştur?

2. Temel sayıltılar ve uygulamalar yönünden algılamalar cinsiyete göre faklılık göstermekte midir?

\section{YÖNTEM}

Beden Eğitimi ve Spor Yüksekokullarındaki, örgütsel kültürün, paylaşılan temel sayıltılar ve örgütsel uygulamaları ile açıklanmaya çalışıldığı bu araştırma, bir alan araştırması olup, betimsel modelde desenlenmiştir.

Bu araştırmanın evrenini, ülkemizin Güney Anadolu Bölgesi'nde yer alan Çukurova, Gaziantep, Sütçü İmam, Mersin ve Mustafa Kemal Üniversitelerinin Beden Eğitimi ve Spor Yüksekokullarındaki çalışanlar oluşturmaktadır. Bu yüksekokullarda çalışanlar arasından, tesadüfü seçilmiş 94 kişi, araştırmamızın örneklem grubunu oluşturmaktadır.

Veri toplama aracı olarak Şişman'ın(1994) ilkokullarda örgüt kültürü üzerine yaptığı araştırma için geliştirdiği iki bölümlük örgütsel kültür anketi, kendisinden izin alınarak kullanılmıştır. Şişman(1994), tarafından anketin geçerliliğinin belirlenmesi için, 15 gün arayla aynı kişilere uygulanmış, Cronbach alfa ve korelasyon katsayısına bakılmıştır. İlk uygulamada, anketin birinci bölümü için Cronbach alfa sayısı .97; ikinci bölümü için de .96 hesaplanmıştır. İki uygulama arasındaki korelasyon katsayısı da birinci bölüm için $r=.97$; ikinci bölüm için $r=.90$ olarak hesaplanmıştır.

Araştırma verilerinin istatistiksel analizleri, SPSS paket programında yapılmıştır. İstatistik analiz olarak, betimsel istatistik ve yordamsal istatistik kullanılmıştır. Farklııklar, "T testi” yapılarak belirlenmiştir.

\section{BULGULAR}

Araştırmamız, \%33 kadın, \%67 erkek çalışanı kapsamıştır. Ayrıca, \%66 akademik, \%23.4 idari, \%10.6 yönetici, çalışan, araştırmaya katılmıştır. Araştırmamızda yöneticiler, müdür ve müdür yardımcıları olarak tanımlanmıştır. Çalışanların kıdem durumuna bakıldığında, \% 49.0 ile 1-9 yıl arasında çalışanlar oluşturduğu için genç bir kadronun Beden Eğitimi ve Spor Yüksekokul'arında (BESYO) var olduğunu söyleyebiliriz.

$\mathrm{Bu}$ bölümde, araştırma probleminin çözümlenmesi amacıyla toplanan verilerin işlenmesiyle elde edilen bulgulara ve bunların yorumlarına yer verilmiştir. Veri toplama aracının birinci bölümünde yer alan paylaşılan temel sayıltılarla ilgili maddelerle, ikinci bölümde yer alan örgütsel uygulamaları ifade eden maddelere ilişkin olarak, örneklem grubundan sağlanan nicel verilerin ortalama ve standart sapma değerleri aşağıda iki ayrı tabloda (Tablo.1 ve Tablo.2) toplu halde gösterilmiştir.

Her Üniversitenin BESYO'larının kendi başlıkları altında tabloların açıklama ve yorumları yapılmıştır. BESYO'ların açıklama ve yorumlarında öncelikle, güçlü kültür alt yapısını oluşturabilecek olan paylaşılan temel sayıltılar verilmiş, ardından zayıf kültür alt yapısını belirleyen temel sayıltılar yer almıştır. Daha sonra güçlü kültürü belirleyen örgütsel uygulamalar ve ardından zayıf örgütsel uygulamaları belirleyen maddeler verilerek yorumları yapılmıştır. 
Tablo 1. Besyo'larda Paylaşılan Temel Sayıltıların Ortalama Ve Standart Sapmaları

\begin{tabular}{|c|c|c|c|c|c|c|c|c|c|c|}
\hline \multirow[b]{2}{*}{ Maddeler } & \multicolumn{2}{|c|}{$\begin{array}{l}\text { Ç.U. } \\
\text { Besyo }\end{array}$} & \multicolumn{2}{|c|}{$\begin{array}{l}\text { G.A.Ü. } \\
\text { Besyo }\end{array}$} & \multicolumn{2}{|c|}{$\begin{array}{l}\text { S.í.Ü. } \\
\text { Besyo }\end{array}$} & \multicolumn{2}{|c|}{$\begin{array}{l}\text { M.Ü. } \\
\text { Besyo }\end{array}$} & \multicolumn{2}{|c|}{$\begin{array}{l}\text { M.K.Ü. } \\
\text { Besyo }\end{array}$} \\
\hline & $\overline{\mathbf{X}}$ & SS & $\overline{\mathbf{X}}$ & SS & $\overline{\mathbf{X}}$ & SS & $\overline{\mathbf{X}}$ & SS & $\overline{\mathbf{X}}$ & SS \\
\hline İnsanlar arasındaki çatışmalar uzlaşılarak çözümlenebilir. & 4.05 & 1.12 & 4.31 & 0.82 & 3.66 & 1.37 & 3.63 & 0.80 & 3.76 & 1.09 \\
\hline $\begin{array}{l}\text { Insanın mesleğinde kendini geliştirmesi için fırsatlar } \\
\text { verilmelidir }\end{array}$ & 4.71 & 0.72 & 4.78 & 0.71 & 4.66 & 0.88 & 4.81 & 0.40 & 4.69 & 0.48 \\
\hline Bir grubun vereceği kararlar, bireysel karalardan daha iyidir & 4.17 & 0.91 & 3.52 & 1.21 & 3.91 & 1.37 & 4.27 & 0.64 & 4.15 & 0.80 \\
\hline Genelde insanlar, çalışmaktan pek hoşlanmazlar & 2.71 & 1.02 & 2.84 & 0.83 & 1.83 & 0.83 & 2.90 & 1.13 & 2.92 & 0.95 \\
\hline Genelde insanlar, pek sorumluluk almak istemezler & 2.89 & 0.94 & 3.26 & 0.65 & 2.33 & 0.98 & 3.18 & 1.16 & 2.92 & 0.86 \\
\hline $\begin{array}{l}\text { Genelde insanlar, kontrol edilmedikleri zaman görevlerini } \\
\text { gereği gibi yapmazlar }\end{array}$ & 2.61 & 1.13 & 2.84 & 1.30 & 2.91 & 1.37 & 3.45 & 0.93 & 2.02 & 1.18 \\
\hline Genelde insanlar, başkalarıyla işbirliği yapma eğilimindedirler & 3.33 & 0.77 & 3.47 & 0.84 & 3.66 & 1.23 & 3.09 & 0.30 & 3.46 & 0.77 \\
\hline $\begin{array}{l}\text { Genelde insanlar, yaratıış itibariyle iyi ve güvenilir } \\
\text { varlıklardır. }\end{array}$ & 3.23 & 0.95 & 3.21 & 0.91 & 3.50 & 1.16 & 3.27 & 0.78 & 3.15 & 1.14 \\
\hline $\begin{array}{l}\text { Yüksekokulda doğru kararlar verebilmek için, ilgili yönetsel } \\
\text { metinlere (yasa, tüzük, yönetmelik) başvurulmalıdır. }\end{array}$ & 4.07 & 1.01 & 4.21 & 0.53 & 4.00 & 1.12 & 4.18 & 0.60 & 4.30 & 0.48 \\
\hline $\begin{array}{l}\text { Yüksekokulda doğru kararlar verebilmek için, üst yöneticilerin } \\
\text { görüşlerine başvurulmalıdır }\end{array}$ & 3.51 & 0.99 & 3.57 & 0.50 & 3.58 & 1.08 & 2.90 & 0.83 & 3.69 & 0.94 \\
\hline $\begin{array}{l}\text { Bir kurumun başarııı olabilmesi için, personel arasında iyi bir } \\
\text { yardımlaşma işbirliği olmalıdır. }\end{array}$ & 4.56 & 0.78 & 4.42 & 0.60 & 4.16 & 1.11 & 4.45 & 0.68 & 4.53 & 0.51 \\
\hline $\begin{array}{l}\text { Bir kurumun başarılı olabilmesi için, herkes görevinde başarılı } \\
\text { olmalıdır }\end{array}$ & 4.10 & 1.02 & 4.42 & 0.50 & 4.00 & 1.12 & 4.18 & 0.75 & 4.23 & 0.83 \\
\hline $\begin{array}{l}\text { Bir kurumun başarılı olabilmesi için, işinde başarılı olanlar } \\
\text { olmayanlara yardım etmelidir }\end{array}$ & 3.79 & 0.92 & 3.73 & 0.93 & 3.50 & 1.44 & 3.81 & 0.98 & 3.15 & 1.21 \\
\hline $\begin{array}{l}\text { Bir kurumun başarııı olabilmesi için, personel arasında sıkı } \\
\text { bir dostluk ve güven olmalıdır }\end{array}$ & 4.61 & 0.71 & 4.36 & 0.68 & 4.41 & 0.99 & 4.18 & 0.87 & 4.00 & 0.81 \\
\hline
\end{tabular}

Tablo 2. Besyo'larda Örgütsel Uygulamaların Ortalama Ve Standart Sapmaları

\begin{tabular}{|c|c|c|c|c|c|c|c|c|c|c|}
\hline \multirow[b]{2}{*}{ Maddeler } & \multicolumn{2}{|c|}{$\begin{array}{l}\text { Ç.U. } \\
\text { Besyo }\end{array}$} & \multicolumn{2}{|c|}{$\begin{array}{l}\text { G.A.Ü. } \\
\text { Besyo }\end{array}$} & \multicolumn{2}{|c|}{$\begin{array}{l}\text { S.i.Ü. } \\
\text { Besyo }\end{array}$} & \multicolumn{2}{|c|}{$\begin{array}{l}\text { M.Ü. } \\
\text { Besyo }\end{array}$} & \multicolumn{2}{|c|}{$\begin{array}{l}\text { M.K.Ü. } \\
\text { Besyo }\end{array}$} \\
\hline & $\overline{\mathbf{X}}$ & SS & $\overline{\mathbf{X}}$ & SS & $\mathbf{X}$ & SS & $\overline{\mathbf{X}}$ & SS & $\mathbf{X}$ & SS \\
\hline $\begin{array}{l}\text { Başarılı olan çalışanlar maddi yada manevi olarak } \\
\text { ödüllendirilir }\end{array}$ & 2.66 & 1.17 & 2.47 & 1.30 & 2.41 & 1.50 & 3.09 & 1.57 & 2.38 & 1.38 \\
\hline $\begin{array}{l}\text { Çalışanların görevle ilgili yapabileceği hatalar, hoşgörü ile } \\
\text { karşınınır }\end{array}$ & 2.48 & 0.94 & 2.57 & 0.83 & 3.00 & 0.95 & 3.27 & 1.10 & 2.69 & 0.94 \\
\hline Yenilik ve değişmeler, öğretmenlerce kolayca kabul edilir & 3.23 & 0.98 & 3.57 & 0.90 & 3.41 & 0.90 & 3.54 & 0.93 & 3.30 & 0.48 \\
\hline $\begin{array}{l}\text { Yüksekokulda her çalışan görevini, sıkı kontrolden uzak bir } \\
\text { ortamda yapar }\end{array}$ & 2.41 & 1.14 & 2.36 & 1.25 & 2.83 & 1.11 & 2.45 & 1.12 & 2.84 & 1.21 \\
\hline $\begin{array}{l}\text { Yüksekokul çalışanları arasında karşılıklı bir dostluk ve güven } \\
\text { hakimdir }\end{array}$ & 2.33 & 0.86 & 2.89 & 1.32 & 2.50 & 1.24 & 3.54 & 0.82 & 3.07 & 0.95 \\
\hline $\begin{array}{l}\text { Öğretim elemanlarının mesleki gelişimi için yönetim her türlü } \\
\text { desteği sağlar }\end{array}$ & 3.41 & 1.18 & 3.10 & 1.41 & 2.58 & 1.50 & 2.45 & 0.68 & 3.61 & 1.04 \\
\hline $\begin{array}{l}\text { Yüksekokulun başarılı olması için herkes üzerine düşeni } \\
\text { yapar }\end{array}$ & 3.02 & 1.08 & 3.31 & 0.94 & 2.83 & 1.40 & 4.00 & 0.63 & 3.92 & 0.95 \\
\hline $\begin{array}{l}\text { Yüksekokuldaki her öğretmen görevle ilgili sorumluluk } \\
\text { almaktan kaçınmaz }\end{array}$ & 2.97 & 0.93 & 3.73 & 0.87 & 2.91 & 1.24 & 3.54 & 1.29 & 3.69 & 0.85 \\
\hline $\begin{array}{l}\text { Yüksekokulda, sonuçlardan çok, formalite, prosedür, ve } \\
\text { kurallara önem verilir }\end{array}$ & 3.61 & 1.06 & 3.52 & 1.21 & 4.00 & 0.85 & 3.00 & 1.09 & 3.30 & 1.18 \\
\hline $\begin{array}{l}\text { Çalışanlar, okulun amaçlarını aynı şekilde anlayıp } \\
\text { yorumlamaktadır }\end{array}$ & 2.87 & 1.08 & 3.21 & 1.13 & 2.66 & 1.23 & 3.27 & 0.90 & 3.69 & 0.48 \\
\hline Mesleki konularda çalışanlar arasında bir yarışma var & 2.87 & 1.15 & 3.21 & 1.18 & 3.00 & 1.20 & 2.27 & 0.78 & 3.38 & 0.86 \\
\hline $\begin{array}{l}\text { Öğretim elemanları arasında iyi bir yardımlaşma ve işbirliği } \\
\text { alışkanlığı vardır }\end{array}$ & 2.43 & 1.02 & 3.00 & 1.05 & 2.75 & 1.48 & 3.27 & 0.78 & 3.46 & 1.12 \\
\hline $\begin{array}{l}\text { Yönetim, öğretim elemanlarının göreviyle olduğu kadar } \\
\text { sosyal yaşantısıyla da ilgilenir }\end{array}$ & 3.25 & 0.72 & 2.78 & 1.18 & 2.25 & 1.28 & 2.09 & 0.83 & 2.76 & 1.09 \\
\hline $\begin{array}{l}\text { Öğretim elemanları, okulla ilgili düşüncelerini çekinmeden } \\
\text { açıklayabilirler }\end{array}$ & 2.66 & 1.13 & 2.89 & 1.19 & 2.91 & 1.44 & 3.00 & 0.89 & 3.69 & 1.18 \\
\hline $\begin{array}{l}\text { Yüksekokulla eğitimle ilgili önemli kararlar, akademik kurulda } \\
\text { alınır }\end{array}$ & 3.79 & 1.30 & 4.00 & 1.10 & 3.08 & 1.44 & 4.09 & 0.94 & 4.15 & 0.89 \\
\hline $\begin{array}{l}\text { Çalışanlar arasındaki çatışmalar, karşııklı anlayış içinde } \\
\text { çoümlenir }\end{array}$ & 2.58 & 1.25 & 3.47 & 1.26 & 2.08 & 1.24 & 3.27 & 1.19 & 3.69 & 0.85 \\
\hline $\begin{array}{l}\text { Görevle ilgili belirsiz ( yasa ve yönetmeliklerde yer almayan ) } \\
\text { durumlarda öğretmenler riski göze alarak kendileri karar } \\
\text { verebilirler }\end{array}$ & 2.35 & 1.03 & 2.84 & 1.16 & 2.83 & 0.71 & 2.45 & 1.03 & 2.38 & 1.12 \\
\hline $\begin{array}{l}\text { Öğretim elemanları, konu merkezli eğitim anlayışından çok, } \\
\text { ögrrenci merkezli eğitim anlayışını benimserler }\end{array}$ & 2.66 & 1.00 & 2.94 & 0.91 & 2.58 & 1.08 & 2.72 & 1.10 & 3.07 & 1.18 \\
\hline
\end{tabular}




\section{Çukurova Üniversitesi BESYO}

Çukurova Üniversitesi BESYO'da yer alan güçlü kültür alt yapısını oluşturacak olan temel sayıltılar şunlardır:

Tablo 1'de "İnsanlar arasındaki çatışmalar uzlaşarak çözümlenebilir $\bar{X}=4.05)$ ile, "İnsanın mesleğinde kendini geliştirmesi için fırsatlar verilmelidir" $(\bar{X}=4.71)$ ile, "Bir grubun vereceği kararlar, bireysel kararlardan daha iyidir" $\bar{X}=4.17$ ) ile, bu temel sayıltılara güçlü olarak katılmaktadırlar. "Genelde insanlar, çalışmaktan pek hoşlanmazlar" $\bar{X}=2.71)$ ile, "Genelde insanlar, pek sorumluluk almak istemezler" $\bar{X}=2.89)$ ile, görüşlerine katılmadıklarını, "Genelde insanlar, kontrol edilmedikleri zaman görevlerini gereği gibi yapmazlar $(\bar{X}=2.61)$ ile, iyi görev yapmak için insanların kontrol edilmesi gerekmediğine inanmaktadırlar.

"Bir kurumun başarılı olabilmesi için, personel arasında iyi bir yardımlaşma işbirliği olmalıdır" $\bar{X}=4.56)$ ile, "Bir kurumun başarılı olabilmesi için, personel arasında sıkı bir dostluk ve güven olmalı" $\bar{X}=4.61)$ ile bu ifadelere güçlü olarak katıldıklarının ifade edildiğini görmekteyiz. "Bir kurumun başarılı olabilmesi için, herkes görevinde başarılı olmalıdır" ( $\bar{X}=4.10$ ) ile kurumun başarısı için herkesin başarısının önemli olduğuna inanılmaktadır.

Çukurova BESYO'da temel sayıltılardan zayıf kültürün alt yapısını oluşturan sonuçlar şunlardır:

Tablo1'de, "Genelde insanlar, başkalarıyla işbirliği yapma eğilimindedirler" $\bar{X}=3.33$ ) ile, "Genelde insanlar, yaratılış itibariyle iyi ve güvenilir varlıklardır" $(\bar{X}=3.23)$ ile, "Yüksekokulda doğru kararlar verebilmek için, üst yöneticilerin görüşlerine başvurulmalıdır"

( $\bar{X}=3.51$ ) ile, kısmen katılmaktadırlar. "Yüksekokulda doğru kararlar verebilmek için, ilgili yönetsel metinlere başvurulmalıdır" $\bar{X}=4.21$ ) ile bu ifadeye güçlü olarak inanmaktadırlar, "Bir kurumun başarılı olabilmesi için, işinde başarılı olanlar olmayanlara yardım etmelidir” $(\bar{X}=3.79)$ ile ara sıra yardım edildiğine inandıkları görülmektedir. görmekteyiz:

Çukurova BESYO'da yapılan uygulamalara baktığımızda, zayıf bir kültürün göstergeleri olarak şu maddeleri

Tablo 2'de, "Başarılı olan çalışanlar maddi yada manevi olarak ödüllendirilir" $\overline{\mathrm{X}}=2.66)$ ile, ara sıra ödüllendirildiklerini, "Çalışanların görevle ilgili yapabileceği hatalar, hoşgörü ile karşılanır" $\bar{X}=2.48)$ ile, hoşgörünün nadiren olduğunu, "Yenilik ve değişmeler, öğretmenlerce kolayca kabul edilir" $\bar{X}=3.23$ ) ile ara sıra kabul görmekte olduğunu, "Yüksekokulda her çalışan görevini, sıkı kontrolden uzak bir ortamda yapar" $\bar{X}=2.41)$ ile, sıkı bir kontrolün olduğunu, "Yüksekokul çalışanları arasında karşılıklı bir dostluk ve güven hakimdir"( $\bar{X}=2.33)$ ile dostluk ve güvenin olmadığını ifade ettiklerini görmekteyiz. "Öğretim elemanlarının mesleki gelişimi için yönetim her türlü desteği sağlar" ( $\bar{X}=3.41$ ) ile, ara sıra sağlandığını, "Yüksek Okulun başarılı olması için herkes üzerine düşeni yapar" $\bar{X}=3.02)$ ile ara sıra yaptığını, "Yüksek Okuldaki her öğretmen görevle ilgili sorumluluk almaktan kaçınmaz" $\bar{X}=2.97)$ ile ara sıra sorumluluk aldıklarını, "Yüksek Okulda, sonuçlardan çok, formalite, prosedür, ve kurallara önem verilir" $\overline{\mathrm{X}}=3.61)$ ile, kurallara uymanın sonuçlardan daha önemli olduğunu, "Çalışanlar, okulun amaçlarını aynı şekilde anlayıp yorumlamaktadır" $\overline{\mathrm{X}}=2.87$ ) aynı şekilde yorumlamadıklarını, "Mesleki konularda çalışanlar arasında bir yarışma $\operatorname{var} "(\bar{X}=2.87)$ ile yarışmanın ara sıra olduğunu ifade etmektedirler.

"Öğretim elemanları arasında iyi bir yardımlaşma ve işbirliği alışkanlığı vardır" $\bar{X}=2.43)$ ile bu işbirliğinin oluşmadığını, "Yönetim, öğretmenin göreviyle olduğu kadar sosyal yaşantısıyla da ilgilenir" $\bar{X}=3.25)$ ile ara sıra ilgilendiğini, "Öğretim elemanları, okulla ilgili düşüncelerini çekinmeden açıklayabilirler" $\bar{X}=2.66)$ ile düşüncelerini rahatça ifade edemediklerini, "Yüksekokulda eğitimle ilgili önemli kararlar, akademik kurulda alınır" ( $\bar{X}=3.79)$ ile kısmen şeklinde ifade edilmiştir. "Çalışanlar arasındaki çatışmalar, karşılıklı anlayış içinde çözümlenir" $\bar{X}=2.58)$ ile nadiren çözümlendiğini, "Görevle ilgili belirsiz durumlarda öğretmenler riski göze alarak kendileri karar verebilirler" $(\bar{X}=2.35)$ ile risk üstlenemediklerini ve "Öğretim elemanları, konu merkezli eğitim anlayışından çok, öğrenci merkezli eğitim anlayışını benimserler” $(\bar{X}=2.66$ ) ile, bu görüşe katılmadıklarını belirterek öğretmen merkezli eğitim anlayışının benimsendiğini görmekteyiz.

Tüm bu sonuçlardan, Çukurova BESYO'da temel sayıltılar olarak güçlü bir kültür oluşturacak bazı inançların varlığına rağmen, uygulamalar açısından zayıf bir kültür tablosundan söz edebiliriz.

\section{Gaziantep Üniversitesi BESYO}

Gaziantep BESYO'da yer alan güçlü kültür alt yapısı olan, temel sayıltılar şunlardır:

Tablo 1'de "İnsanlar arasındaki çatışmaların uzlaşılarak çözümlenebilir" $\bar{X}=4.31$ ) ile, "İnsanın mesleğinde kendini geliştirmesi için fırsatlar verilmelidir" $(\bar{X}=4.78)$ ile, "Bir kurumun başarılı olabilmesi için, personel arasında iyi bir yardımlaşma işbirliği olmalıdır" ( $\bar{X}=4.42$ ) ile, "Bir kurumun başarılı olabilmesi için, personel arasında sıkı bir dostluk ve güven olmalı” $\bar{X}=4.36)$ ile, bu ifadelere güçlü olarak katıldıklarının ifade edildiğini görmekteyiz. 
"Genelde insanlar, çalışmaktan pek hoşlanmazlar" $\bar{X}=2.84)$ ile, insanların çalışmaktan hoşlanabileceklerini ve "Bir kurumun başarılı olabilmesi için, herkes görevinde başarılı olmalıdır" $\bar{X}=4.42)$ ile kurumun başarısı için herkesin başarısının önemli olduğuna inanıldığını söyleyebiliriz.

Gaziantep BESYO'da temel sayıltılardan zayıf kültür alt yapısını oluşturan sonuçlar şunlardır:

Tablo 1'de, "Bir grubun vereceği kararlar, bireysel kararlardan daha iyidir"( $\bar{X}=3.52)$ ile, grup kararlarının kısmen iyi olduğuna, "Genelde insanlar, pek sorumluluk almak istemezler" $\bar{X}=3.26)$ temel sayıltısına kısmen katıldıkları, "Genelde insanlar, kontrol edilmedikleri zaman görevlerini gereği gibi yapmazlar" $\bar{X}=2.84$ ) ile, insanların kontrol edilmesi gerektiğine inanmakta olduklarını belirtebiliriz. "Genelde insanlar, başkalarıyla işbirliği yapma eğilimindedirler” $\overline{\mathrm{X}}=3.47)$ ile, "Genelde insanlar, yaratılış itibariyle iyi ve güvenilir varlıklardır"( $\bar{X}=3.21$ ) ile kısmen katılmaktadırlar.

"Yüksekokulda doğru kararlar verebilmek için, üst yöneticilerin görüşlerine başvurulmalıdır" $\bar{X}=3.57)$ ile, kısmen katılmaktadırlar. "Yüksekokulda doğru kararlar verebilmek için, ilgili yönetsel metinlere başvurulmalıdır" $\bar{X}=4.21)$ ile, bu ifadeye güçlü olarak inanmakta olduklarını, "Bir kurumun başarılı olabilmesi için, işinde başarılı olanlar olmayanlara yardım etmelidir" ( $\bar{X}=3.73$ ) ile kısmen görüşünde oldukları görülmektedir. görmekteyiz:

Gaziantep BESYO'da yapılan uygulamalara baktığımızda, güçlü bir kültürün göstergeleri olarak şu maddeyi

Tablo 2'de, Güçlü örgüt göstergelerinden biri olan "Yüksekokulda eğitimle ilgili önemli kararlar, akademik kurulda alınır” $\bar{X}=4.00$ ) ile önemli kararların akademik kurulda alındığını belirtmekte olduklarını görüyoruz. görmekteyiz:

Gaziantep BESYO'da yapılan uygulamalara baktığımızda, zayıf bir kültürün göstergeleri olarak şu maddeleri

"Tablo 2'de, "Başarılı olan çalışanlar maddi yada manevi olarak ödüllendirilir" ( $\bar{X}=2.47)$ ile nadiren ödüllendirildiklerini, "Çalışanların görevle ilgili yapabileceği hatalar, hoşgörü ile karşılanır" $\bar{X}=2.57)$ ile, hoşgörünün nadiren gösterildiğini, "Yenilik ve değişmeler, öğretmenlerce kolayca kabul edilir" $\bar{X}=3.57)$ ile ara sıra kabul görmekte olduğunu, "Yüksek Okulda her çalışan görevini, sıkı kontrolden uzak bir ortamda yapar" ( $\bar{X}=2.36)$ ile, sıkı bir kontrolün olduğunu, "Yüksekokul çalışanları arasında karşılıklı bir dostluk ve güven hakimdir" $\bar{X}=2.89)$ ile, dostluk ve güvenin olmadığını ifade ettiklerini görmekteyiz.

"Öğretim elemanlarının, mesleki gelişimi için yönetim, her türlü desteği sağlar" ( $\bar{X}=3.10)$ ile, "Yüksek Okulun başarılı olması için herkes üzerine düşeni yapar" $\bar{X}=3.31$ ) ile, ara sıra yaptığını, "Yüksek Okuldaki her öğretmen görevle ilgili sorumluluk almaktan kaçınmaz" $\bar{X}=3.73)$ ile, ara sıra sorumluluk aldıklarını, "Yüksek Okulda, sonuçlardan çok, formalite, prosedür, ve kurallara önem verilir" $(\bar{X}=3.52)$ ile, kurallara uymanın, sonuçlardan önemli olduğunu, "Çalışanlar, okulun amaçlarını aynı şekilde anlayıp yorumlamaktadır" ( $\bar{X}=3.21$ ) ile, kısmen aynı şekilde yorumladıklarını, "Mesleki konularda çalışanlar arasında bir yarışma var" ( $\bar{X}=3.21$ ) ile yarışmanın kısmen olduğuna, inandıklarını söyleyebiliriz.

"Öğretim elemanları arasında iyi bir yardımlaşma ve işbirliği alışkanlığı vardır" $(\bar{X}=3.00)$ ile bu işbirliğinin kısmen oluştuğunu, "Yönetim, öğretim elemanının göreviyle olduğu kadar sosyal yaşantısıyla da ilgilenir" $(\bar{X}=2.78)$ ile ara sıra ilgilendiğini, "Öğretim elemanları, okulla ilgili düşüncelerini çekinmeden açıklayabilirler" $\bar{X}=2.89)$ ile düşüncelerini çekinmeden ifade edemediklerini, "Çalışanlar arasındaki çatışmalar, karşılıklı anlayış içinde çözümlenir" $(\bar{X}=3.47)$ ile ara sıra çözümlendiğini, "Görevle ilgili belirsiz durumlarda öğretmenler riski göze alarak kendileri karar verebilirler" $(\bar{X}=2.84)$ ile risk üstlenemediklerini ve "Öğretim elemanları, konu merkezli eğitim anlayışından çok, öğrenci merkezli eğitim anlayışını benimserler” $\bar{X}=2.94$ ) ile, öğretmen merkezli eğitim anlayışının benimsendiğini görmekteyiz.

Tüm bu sonuçlardan, Gaziantep BESYO'da temel sayıltılar olarak güçlü bir kültür oluşturacak bazı inançların varlığına rağmen, uygulamalar açısından zayıf bir kültür tablosu ile karşı karşıya olduğumuzu söyleyebiliriz.

\section{Sütçü İmam Üniversitesi BESYO}

Sütçü İmam BESYO'da yer alan güçlü kültür alt yapısını oluşturan temel sayıltılar şunlardır:

Tablo1'de, "İnsanın mesleğinde kendini geliştirmesi için fırsatlar verilmelidir” ( $\bar{X}=4.66$ ) ile, "Genelde insanlar, kontrol edilmedikleri zaman görevlerini gereği gibi yapmazlar" $\bar{X}=2.91$ ) ile, insanların görevlerini iyi yapmaları için kontrol edilmeleri gerekmediğine inanmaktadırlar. "Genelde insanlar, çalışmaktan pek hoşlanmazlar" $\overline{\mathrm{X}}=1.83)$ ile, "Genelde insanlar, pek sorumluluk almak istemezler" $\bar{X}=2.33$ ) ile, bu ifadelere katılmamaktadırlar.

"Bir kurumun başarılı olabilmesi için, personel arasında iyi bir yardımlaşma işbirliği olmalıdır" $\bar{X}=4.16)$ ile, "Bir kurumun başarılı olabilmesi için, personel arasında sıkı bir dostluk ve güven olmalı" $\bar{X}=4.41)$ ile, bu ifadelere güçlü olarak katıldıklarının ifade edildiğini görmekteyiz. "Bir kurumun başarılı olabilmesi için, herkes görevinde başarılı olmalıdır" ( $\bar{X}=4.00$ ) ile kurumun başarısı için herkesin başarısının önemli olduğuna inanılmaktadır. 
Sütçü İmam BESYO'da temel sayıltılardan zayıf kültür alt yapısını oluşturan sonuçlar şunlardır:

Tablo1'de, "Insanlar arasındaki çatışmaların uzlaşılarak çözümlenebilir" $\bar{X}=3.66)$ ile, "Bir grubun vereceği kararlar, bireysel karalardan daha iyidir" $(\bar{X}=3.91)$ ile, "Genelde insanlar, başkalarıyla işbirliği yapma eğilimindedirler" $\bar{X}=3.66$ ) ile, "Genelde insanlar, yaratılış itibariyle iyi ve güvenilir varlıklardır" $(\bar{X}=3.50)$ ile, "Yüksekokulda doğru kararlar verebilmek için, üst yöneticilerin görüşlerine başvurulmalıdır" $\bar{X}=3.58)$ ile, bu ifadelere kısmen katılmaktadırlar. "Yüksekokulda doğru kararlar verebilmek için, ilgili yönetsel metinlere başvurulmalıdır" $\bar{X}=4.00)$ ile, bu ifadeye güçlü olarak katıldıklarını belirtmektedirler. "Bir kurumun başarılı olabilmesi için, işinde başarılı olanlar, olmayanlara yardım etmelidir" $\bar{X}=3.50)$ ile, yardımlaşmanın düşük olduğunu ifade edebiliriz. görmekteyiz:

Sütçü İmam BESYO'da yapılan uygulamalara baktığımızda, güçlü bir kültürün göstergeleri olarak şu maddeyi

Tablo 2'de, "Yüksekokulda her çalışan görevini, sıkı kontrolden uzak bir ortamda yapar" ( $\bar{X}=2.83$ ) ile, sıkı bir kontrolün olmadığını söyleyebiliriz. görmekteyiz:

Sütçü İmam BESYO'da yapılan uygulamalara baktığımızda, zayıf bir kültürün göstergeleri olarak şu maddeleri

Tablo 2'de, "Başarılı olan çalışanlar maddi yada manevi olarak ödüllendirilir" $(\bar{X}=2.41)$ ile ara sıra ödüllendirildiklerini, "Çalışanların görevle ilgili yapabileceği hatalar, hoşgörü ile karşılanır" $\bar{X}=3.00)$ ile, hoşgörünün kısmen gösterildiğini, "Yenilik ve değişmeler, öğretmenlerce kolayca kabul edilir" $\bar{X}=3.41)$ ile, ara sıra kabul görmekte olduğunu, "Yüksekokul çalışanları arasında karşılıklı bir dostluk ve güven hakimdir" ( $\bar{X}=2.50)$ ile, dostluk ve güvenin olmadığını ifade edebiliriz. "Öğretim elemanlarını mesleki gelişimi için yönetim her türlü desteği sağlar" $\bar{X}=2.58)$ ile, "Yüksek Okulun başarılı olması için herkes üzerine düşeni yapar” $\bar{X}=2.83$ ) ile ara sıra yaptığını, "Yüksekokuldaki her öğretmen görevle ilgili sorumluluk almaktan kaçınmaz" $(\bar{X}=2.91)$ ile, ara sıra sorumluluk aldıklarını, "Yüksekokulda, sonuçlardan çok, formalite, prosedür, ve kurallara önem verilir" ( $\bar{X}=4.00)$ ile, kurallara uymanın sonuçlardan önemli olduğuna inandıklarını belirtebiliriz.

"Çalışanlar, okulun amaçlarını aynı şekilde anlayıp yorumlamaktadır" $(\bar{X}=2.66)$ ile, aynı şekilde yorumlamadıklarını, "Mesleki konularda çalışanlar arasında bir yarışma var" ( $\bar{X}=3.00$ ) ile, yarışmanın kısmen olduğunu ifade etmektedirler. "Öğretim elemanları arasında iyi bir yardımlaşma ve işbirliği alışkanlığı vardır" $\bar{X}=2.75)$ ile, bu işbirliğinin oluşmadığını, "Yönetim, öğretim elemanının göreviyle olduğu kadar sosyal yaşantısıyla da ilgilenir" ( $\bar{X}=2.25)$ ile, nadiren ilgilendiğini, Öğretim elemanı, okulla ilgili düşüncelerini çekinmeden açıklayabilirler $(\bar{X}=2.91)$ ile, düşüncelerini açıkça ifade edemediklerini, "Yüksekokulda eğitimle ilgili önemli kararlar, akademik kurulda alınır” $\bar{X}=3.08$ ) ile, kısmen alındığını görmekteyiz. "Çalışanlar arasındaki çatışmalar, karşılıklı anlayış içinde çözümlenir" $(\bar{X}=2.08)$ ile, nadiren çözümlendiğini, "Görevle ilgili belirsiz almayan durumlarda öğretmenler riski göze alarak kendileri karar verebilirler" $(\bar{X}=2.83)$ ile, risk üstlenemediklerini ve "Öğretim elemanı, konu merkezli eğitim anlayışından çok, öğrenci merkezli eğitim anlayışını benimserler” $(\bar{X}=2.58)$ ile, öğretmen merkezli eğitim anlayışının benimsendiğini söyleyebiliriz.

Tüm bu sonuçlardan, Sütçü İmam BESYO'da temel sayıltılar olarak güçlü bir kültür oluşturacak bazı inançların varlığına rağmen, uygulamalar açısından zayıf bir kültür tablosundan söz edebiliriz.

\section{Mersin Üniversitesi BESYO}

Mersin Üniversitesi BESYO'da yer alan güçlü kültür alt yapısını oluşturan temel sayıltılar şunlardır:

Tablo1'de, "İnsanın mesleğinde kendini geliştirmesi için fırsatlar verilmelidir" ( $\bar{X}=4.81$ ) ile, "Bir grubun vereceği kararlar, bireysel kararlardan daha iyidir" $\bar{X}=4.27)$ ile, bu ifadelere güçlü olarak katılmaktadırlar. "Genelde insanlar, çalışmaktan pek hoşlanmazlar" ( $\bar{X}=2.90)$ ile, bu ifadeye katılamadıklarını belirtmişlerdir. "Bir kurumun başarılı olabilmesi için, personel arasında iyi bir yardımlaşma işbirliği olmalıdır"( $\bar{X}=4.45)$ ile, "Bir kurumun başarılı olabilmesi için, personel arasında sıkı bir dostluk ve güven olmalı" $\bar{X}=4.18)$ ile, bu ifadelere güçlü olarak katıldıklarını görmekteyiz. "Yüksekokulda doğru kararlar verebilmek için, üst yöneticilerin görüşlerine başvurulmalıdır" $\bar{X}=2.90)$ temel sayıltısına katılmamaktadırlar. Yöneticilere başvurulmadan da doğru karar verilebileceğine inandıklarını söyleyebiliriz. "Bir kurumun başarılı olabilmesi için, herkes görevinde başarılı olmalıdır" ( $\bar{X}=4.18$ ) ile, kurumun başarısı için herkesin başarısının önemli olduğuna inanılmaktadır.

Mersin BESYO'da temel sayıltılardan zayıf kültür alt yapısını oluşturan sonuçlar şunlardır:

Tablo1'de "İnsanlar arasındaki çatışmaların uzlaşılarak çözümlenebilir” $\bar{X}=3.63$ ) ile, "Genelde insanlar, başkalarıyla işbirliği yapma eğilimindedirler" $\overline{\mathrm{X}}=3.09)$ ile, "Genelde insanlar, yaratılış itibariyle iyi ve güvenilir varlıklardır" 
$(\bar{X}=3.27)$ ile, "Genelde insanlar, pek sorumluluk almak istemezler" $(\bar{X}=3.18)$ ile, "Genelde insanlar, kontrol edilmedikleri zaman görevlerini gereği gibi yapmazlar" $(\overline{\mathrm{X}}=3.45)$ ile, bu ifadelere kısmen katılmaktadırlar. "Yüksekokulda doğru kararlar verebilmek için, ilgili yönetsel metinlere başvurulmalıdı" $(\bar{X}=4.18)$ ile bu ifadeye güçlü olarak inanmakta olduklarını görüyoruz. "Bir kurumun başarıı olabilmesi için, işinde başarıı olanlar olmayanlara yardım etmelidir” $(\bar{X}=3.81)$ ile, yardımlaşmanın düşük olduğunu ifade edebiliriz. görmekteyiz:

Mersin BESYO'da yapılan uygulamalara baktığımızda, güçlü bir kültürün göstergeleri olarak şu maddeleri

Tablo 2'de, "Yüksekokulda her çalışan görevini, sıkı kontrolden uzak bir ortamda yapar" $\bar{X}=2.45)$ ile, sıkı bir kontrolün olmadığııı, "Yüksekokulun başarııı olması için herkes üzerine düşeni yapar" $(\bar{X}=4.00)$ ile, üzerine düşen görevleri yaptıkları, "Yüksekokulda eğitimle ilgili önemli kararlar, akademik kurulda alııı" $(\bar{X}=4.09)$ ile, çoğunlukla alındığına inanmaktadırlar. görmekteyiz:

Mersin BESYO'da yapılan uygulamalara baktığımızda, zayıf bir kültürün göstergeleri olarak şu maddeleri

Tablo 2'de, "Başarıı olan çalışanlar maddi yada manevi olarak ödüllendirilir" ( $\overline{\mathrm{X}}=3.09)$ ile ara sıra ödüllendirildiklerini, "Çalışanların görevle ilgili yapabileceği hatalar, hoşgörü ile karşılanır” $(\bar{X}=3.27)$ ile, hoşgörünün ara sıra gösterildiğini, "Yenilik ve değişmeler, öğretmenlerce kolayca kabul edilir" $(\bar{X}=3.54)$ ile ara sıra kabul görmekte olduğunu, "Yüksekokul çalışanları arasında karşılıklı bir dostluk ve güven hakimdir" ( $\overline{\mathrm{X}}=3.54$ ) ile dostluk ve güvenin yeterince olmadığını söyleyebiliriz.

"Öğretim elemanlarının mesleki gelişimi için yönetim her türlü desteği sağlar" $(\bar{X}=2.45)$ ile, nadiren destek sağladığını, "Yüksekokuldaki her öğretmen görevle ilgili sorumluluk almaktan kaçınmaz" $(\bar{X}=3.54)$ ile ara sıra sorumluluk aldıklarını, "Yüksekokulda, sonuçlardan çok, formalite, prosedür, ve kurallara önem verilir" $(\bar{X}=3.00)$ ile, kurallara uymanın sonuçlardan daha önemli olduğunu, "Çalışanlar, okulun amaçlarını aynı şekilde anlayıp yorumlamaktadır" $(\bar{X}=3.27)$ aynı şekilde yorumlamadıklarını, "Mesleki konularda çalışanlar arasında bir yarışma $\operatorname{vardır}(\bar{X}=2.27)$ ile yarışmanın olmadığını ifade edebiliriz. "Öğretim elemanları arasında iyi bir yardımlaşma ve işbirliği alışkanlığı vardır” $(\bar{X}=3.27)$ ile, bu işbirliğinin ara sıra yapılabildiğini, "Yönetim, öğretmenin göreviyle olduğu kadar sosyal yaşantısıyla da ilgilenir" $(\bar{X}=2.09)$ ile ilgilenilmediğini, "Öğretim elemanları, okulla ilgili düşüncelerini çekinmeden açıklayabilirler" $(\bar{X}=3.00)$ ile, düşüncelerini rahatça ifade edemediklerini, "Çalışanlar arasındaki çatışmalar, karşılıklı anlayış içinde çözümlenir" ( $\bar{X}=3.27$ ) ile arasıra çözümlendiğini, "Görevle ilgili belirsiz (yasa ve yönetmeliklerde yer almayan) durumlarda öğretmenler riski göze alarak kendileri karar verebilirler" ( $\bar{X}=2.45)$ ile, risk üstlenemediklerini ve "Öğretim elemanları, konu merkezli eğitim anlayışından çok, öğrenci merkezli eğitim anlayışını benimserler" $(\bar{X}=2.72)$ ile, öğretmen merkezli eğitim anlayışının benimsendiğini söyleyebiliriz.

Tüm bu sonuçlardan, Mersin BESYO'da temel sayıltılar olarak güçlü bir kültür oluşturacak bazı inançların varlığına rağmen, uygulamalar açısından zayıf bir kültür tablosu ile karşı karşıya olduğumuzdan sözedebiliriz.

\section{Mustafa Kemal Üniversitesi BESYO}

Mustafa Kemal Üniversitesi BESYO'da yer alan güçlü kültür alt yapısını oluşturan temel sayıltılar şunlardır:

Tablo1'de, "İnsanın mesleğinde kendini geliştirmesi için fırsatlar verilmelidir" $(\bar{X}=4.69)$ ile, "Bir grubun vereceği kararlar, bireysel karalardan daha iyidir" ( $\bar{X}=4.15)$ ile, bu ifadelere güçlü olarak katılmaktadırlar. "Genelde insanlar, kontrol edilmedikleri zaman görevlerini gereği gibi yapmazlar" $(\bar{X}=2.92)$ ile, insanların görevlerini iyi yapmaları için kontrol edilmesi gerekmediğine inandıklarını söyleyebiliriz. "Bir kurumun başarılı olabilmesi için, personel arasında iyi bir yardımlaşma işbirliği olmalıdır" $(\bar{X}=4.53)$ ile, "Bir kurumun başarılı olabilmesi için, personel arasında sıkı bir dostluk ve güven olmalı” $(\bar{X}=4.00)$ ile bu ifadelere güçlü olarak katıldıklarının görmekteyiz.

"Genelde insanlar, çalışmaktan pek hoşlanmazlar" $(\bar{X}=2.92)$ ile, Genelde insanlar, pek sorumluluk almak istemezler ( $\overline{\mathrm{X}}=2.92)$ ile, ifadesine katılmadıklarını görüyoruz. Bu durumda insanların, çalışmaktan hoşlandıklarına ve sorumluluk alabileceklerine inandıklarını, "Bir kurumun başarıı olabilmesi için, herkes görevinde başarıı olmalıdır"( $\overline{\mathrm{X}}=4.23)$ ile, kurumun başarısı için herkesin başarısının önemli olduğuna inandıklarını belirtebiliriz.

Mustafa Kemal Üniversitesi BESYO'da temel sayıltılardan zayıf kültür alt yapısını oluşturan sonuçlar şunlardır:

Tablo1'de, "Insanlar arasındaki çatışmalar uzlaşarak çözümlenebilir" $(\bar{X}=3.76)$ ile, "Genelde insanlar, başkalarıyla işbirliği yapma eğilimindedirler" $(\bar{X}=3.46)$ ile, "Genelde insanlar, yaratılış itibariyle iyi ve güvenilir varlıklardır" $(\bar{X}=3.15)$ ile, "Yüksekokulda doğru kararlar verebilmek için, üst yöneticilerin görüşlerine başvurulmalıdır" $\bar{X}=3.69)$ ile, 
kısmen katılmaktadırlar. "Yüksekokulda doğru kararlar verebilmek için, ilgili yönetsel metinlere başvurulmalıdır" $\bar{X}=4.30)$ ile bu ifadeye güçlü olarak katılmaktadırlar. Bu durumda karar vericilerin kendi başlarına doğru karar vermelerinde endişeleri olduğunu söyleyebiliriz. "Bir kurumun başarılı olabilmesi için, işinde başarılı olanlar olmayanlara yardım etmelidir” ( $\bar{X}=3.15$ ) ile, yardımlaşmanın düşük olduğunu ifade edebiliriz.

Mustafa Kemal BESYO'da yapılan uygulamalara baktığımızda, güçlü bir kültürün göstergelerinden olan şu maddeyi görmekteyiz:

Tablo 2'de, "Yüksekokulda eğitimle ilgili önemli kararlar, akademik kurulda alınır ( $\bar{X}=4.15)$ ile, çoğu zaman kararların akademik kurulda alındığını söyleyebiliriz.

Mustafa Kemal BESYO'da yapılan uygulamalara baktığımızda, zayıf bir kültürün göstergeleri olarak şu maddeleri görmekteyiz:

Tablo 2'de, "Başarılı olan çalışanlar maddi yada manevi olarak ödüllendirilir" ( $\bar{X}=2.38$ ) ile nadiren ödüllendirildiklerini, "Çalışanların görevle ilgili yapabileceği hatalar, hoşgörü ile karşılanır” $\bar{X}=2.69)$ ile, hoşgörünün gösterilmediği, "Yenilik ve değişmeler, öğretmenlerce kolayca kabul edilir" $\bar{X}=3.30)$ ile, ara sıra kabul görmekte olduğunu, "Yüksekokulda her çalışan görevini, sıkı kontrolden uzak bir ortamda yapar ( $\bar{X}=2.84)$ ile, sıkı bir kontrolün olduğunu, "Yüksekokul çalışanları arasında karşılıklı bir dostluk ve güven hakimdir" ( $\bar{X}=3.07)$ ile, dostluk ve güvenin kısmen yaşandığını belirtebiliriz.

"Öğretim elemanlarının mesleki gelişimi için yönetim her türlü desteği sağlar" ( $\bar{X}=3.61)$ ile, ara sıra destek sağlandığını, "Yüksekokulun başarılı olması için herkes üzerine düşeni yapar" ( $\bar{X}=3.92)$ ile, üzerine düşen görevleri ara sıra yaptıklarını, "Yüksekokulda "ki her öğretmen görevle ilgili sorumluluk almaktan kaçınmaz" ( $\bar{X}=3.69)$ ile ara sıra sorumluluk aldıklarını, "Yüksekokulda, sonuçlardan çok, formalite, prosedür, ve kurallara önem verilir" $(\bar{X}=3.30)$ ile, kurallara uymanın sonuçlardan daha önemli olduğunu, "Çalışanlar, yüksek okulun amaçlarını aynı şekilde anlayıp yorumlamaktadır" $(\overline{\mathrm{X}}=3.69$ ) aynı şekilde yorumlamadıklarını, "Mesleki konularda çalışanlar arasında bir yarışma vardır" ( $\bar{X}=3.38)$ ile yarışmanın ara sıra yaşandığını söyleyebiliriz.

"Öğretim elemanları arasında iyi bir yardımlaşma ve işbirliği alışkanlığı vardır" ( $\bar{X}=3.46)$ ile, bu işbirliğinin kısmen oluştuğu, "Yönetim, öğretim elemanının göreviyle olduğu kadar sosyal yaşantısıyla da ilgilenir" $(\bar{X}=2.76)$ ile, ilgilenilmediğini, "Öğretim elemanı, okulla ilgili düşüncelerini çekinmeden açıklayabilirler" $\bar{X}=3.69)$ ile, düşüncelerini rahatça ifade edemediklerini, "Çalışanlar arasındaki çatışmalar, karşılıklı anlayış içinde çözümlenir" $\bar{X}=3.69)$ ile arasıra çözümlendiğini, "Görevle ilgili belirsiz durumlarda öğretmenler riski göze alarak kendileri karar verebilirler” $\bar{X}=2.38)$ ile, risk üstlenemediklerini ve "Öğretim elemanı, konu merkezli eğitim anlayışından çok, öğrenci merkezli eğitim anlayışını benimserler” $\bar{X}=3.07$ ) ile, öğretmen merkezli eğitim anlayışının benimsendiğini söyleyebiliriz.

Tüm bu sonuçlardan, Mustafa Kemal BESYO'da temel sayıltılar olarak güçlü bir kültür oluşturacak bazı inançların varlığına rağmen, uygulamalar açısından zayıf bir kültür tablosundan söz edebiliriz.

\section{Cinsiyet Değişkenine Göre Paylaşılan Temel Sayıltı ve Uygulamalar}

Bu bölümde, Besyo'lardaki bazı paylaşılan sayıltılarla ve bazı uygulamalara ilişkin algıların ortalamaları yüksekokullarda ayrı ayrı "T testi” yapılarak karşılaştırıımıştır. Sonuçlar Tablo 8'de verilmiştir.

Tüm Besyolar'da çalışanların, temel sayıltılar ve örgütsel uygulamaların, cinsiyet değişkenine göre arasındaki fark "T testi" ile belirlenmiştir.

Tablo 3'deki maddelerde ifade edilen temel sayıltılar cinsiyete göre farklılaşmıştır. "Bir grubun vereceği kararlar, bireysel kararlardan daha iyidir” sayıltısında bayanlar, grup kararlarının kısmen iyi olduğuna katılırken, erkekler güçlü olarak katılmaktadırlar. Toplumumuzda kadının iş yaşamına katılımının çok yeni olduğu düşünülürse, iş yaşamında grup olarak bir araya gelmeleri ve üretime katılmaları zeminin erkekler kadar oluşmaması böyle bir sonuca yol açmış olabilir. "İ̧̧ ve oyun birbirinin aynı olan şeydir" sayıltısındaki farklılığın, erkeklerin iş yaşamını oyun gibi algılayarak daha zevk aldıklarından, kadınların iş dışında da bir çok işe yetişmek gibi sorumluluk üstlenmelerinden kaynaklandığını söyleyebiliriz. "Genelde insanlar, çalışmaktan pek hoşlanmazlar" sayıltısına ve "Genelde insanlar, pek sorumluluk almak istemezler" sayıltısına, bayanlar kısmen katılırken, erkekler katılmamaktadır. Kadınların iş yaşamından pek hoşnut olmamaları ve karşılarındaki cinsten sorumluluklarını yerine getirme konusundaki olumsuz deneyimleri bu farklılığa neden olmuş olabilir. "Genelde insanlar, yaratılış itibariyle iyi ve güvenilir varlıklardır" sayıltısına, bayanlar katılmazken, erkekler kısmen katılmaktadırlar. Bayanların toplumda kendilerini güvende hissetmemeleri bu farklıığı oluşturmuştur diyebiliriz. "Bir kurumun başarılı olabilmesi için, personel arasında işle ilgili konularda sürekli bir yarış olmalıdır" sayıltısına bayanlar katılmamakta, erkekler kısmen katılmaktadırlar. Erkeklerin, İş yaşamında liderliği elinde bulundurmaları ve bayanlardan daha yarışmacı kimlik taşımaları bu farklıı̆ı̆ın nedeni olabilir. 
BiLiR, P., AY, Ü., ÇELiK GÜRBÜZ, T., "Beden Eğitimi ve Spor Yüksekokullarında Örgüt Kültürü"

Tablo 3. Besyo'larda Paylaşılan Temel Sayıltılar ve Uygulamaların Cinsiyet Değişkenine Göre Algılanması “T Testi”

\begin{tabular}{|c|c|c|c|c|c|c|}
\hline Temel Sayıltılar & Cinsiyet & $\mathbf{N}$ & $\overline{\mathbf{X}}$ & SS & $\mathbf{T}$ & $\mathbf{P}$ \\
\hline \multirow{2}{*}{ Bir grubun vereceği kararlar, bireysel kararlardan daha iyidir } & Bayan & 30 & 3.56 & 1.22 & \multirow[b]{2}{*}{-0.32} & \multirow[b]{2}{*}{0.00} \\
\hline & Erkek & 63 & 4.22 & 0.85 & & \\
\hline \multirow[t]{2}{*}{ Iş ve oyun birbirinin aynı olan şeydir. } & Bayan & 30 & 2.16 & 1.17 & \multirow[b]{2}{*}{-2.19} & \multirow[b]{2}{*}{0.03} \\
\hline & Erkek & 63 & 2.76 & 1.24 & & \\
\hline \multirow[t]{2}{*}{ Genelde insanlar, çalışmaktan pek hoşlanmazlar } & Bayan & 30 & 3.00 & 0.90 & \multirow[b]{2}{*}{2.04} & \multirow[b]{2}{*}{0.04} \\
\hline & Erkek & 63 & 2.55 & 1.01 & & \\
\hline \multirow[t]{2}{*}{ Genelde insanlar, pek sorumluluk almak istemezler } & Bayan & 30 & 3.23 & 0.77 & \multirow[b]{2}{*}{2.04} & \multirow[b]{2}{*}{0.04} \\
\hline & Erkek & 63 & 2.80 & 0.98 & & \\
\hline \multirow[t]{2}{*}{ Genelde insanlar, yaratılış itibariyle iyi ve güvenilir varlıklardır. } & Bayan & 30 & 2.86 & 0.86 & \multirow[b]{2}{*}{-2.87} & \multirow[b]{2}{*}{0.00} \\
\hline & Erkek & 63 & 3.46 & 0.96 & & \\
\hline \multirow{2}{*}{$\begin{array}{l}\text { Bir kurumun başarılı olabilmesi için, personel arasında işle ilgili konularda sürekli bir yarış } \\
\text { olmalıdır. }\end{array}$} & Bayan & 30 & 2.83 & 1.08 & \multirow[b]{2}{*}{-2.25} & \multirow[b]{2}{*}{0.02} \\
\hline & Erkek & 63 & 3.39 & 1.14 & & \\
\hline \multicolumn{7}{|l|}{ Uygulamalar } \\
\hline \multirow[t]{2}{*}{ Yüksekokulda her çalışan görevini, sıkı kontrolden uzak ortamda yapar } & Bayan & 30 & 2.10 & 1.02 & \multirow[b]{2}{*}{-2.43} & \multirow[b]{2}{*}{0.01} \\
\hline & Erkek & 63 & 2.71 & 1.18 & & \\
\hline \multirow[t]{2}{*}{ Yüksekokulun başarılı olması için herkes üzerine düşeni yapar } & Bayan & 30 & 2.96 & 1.15 & \multirow[b]{2}{*}{-2.03} & \multirow[b]{2}{*}{0.04} \\
\hline & Erkek & 63 & 3.46 & 1.05 & & \\
\hline \multirow[t]{2}{*}{ Yüksekokulda sonuçlardan çok formalite, prosedür, kurallara önem verilir } & Bayan & 30 & 3.86 & 0.93 & \multirow[b]{2}{*}{2.07} & \multirow[b]{2}{*}{0.04} \\
\hline & Erkek & 63 & 3.36 & 1.15 & & \\
\hline
\end{tabular}

Tablo 3'de görüldüğü gibi "Yüksekokulda her çalışan görevini, sıkı kontrolden uzak ortamda yapar" uygulamasına bayanlar katılmazken, erkekler kısmen katılmaktadırlar. Yıllarca İş dışındaki yaşamında da sıkı kontrol altında yaşamış bayanların bu duruma alışmış olmaları, erkeklerden farklı düşünmeye yol açmış olabilir. "Yüksekokulun başarılı olması için herkes üzerine düşeni yapar" uygulamasına bayanlar katılmamakta, erkekler kısmen katılmaktadırlar. bayanların iş dışındaki yaşantılarındaki erkekler ile ilgili deneyimleri bu farklı algılamaya yol açmış olabilir. "Yüksekokulda sonuçlardan çok formalite, prosedür, kurallara önem verilir" uygulaması algılanmasındaki farklılık, formalite prosedür ve kurallara kadınların daha fazla uymaları konusundaki baskıdan kaynaklandığını ifade edebiliriz.

\section{TARTIŞMA VE SONUÇ}

Araştırmamızın bulgularında paylaşılan temel sayılılara baktığımızda, çalışanların çatışma durumunda uzlaşmadan yana oldukları, çalışanların meslek gelişimleri için fırsatlar verilmesi, kurumun başarısı için işbirliği, yardımlaşma ve sıkı dostluk, güvenden yana olduklarını, tüm BESYO'larda görmekteyiz. Ayrıca, çalışanlar, iyi iş yapılması için sıkı kontrolün olmasına gerek olmadığına inanmaktadır. İnsanların çalışmaktan hoşlanabilecekleri ve bu konuda sorumluluk alabilecekleri ve kurumun başarı için herkesin başarılı olması gerektiği inancı da bulgularımız arasındadır. Bu durumda, bazı temel sayıltıların güçlü bir kültürün kriterleri olduğundan, sosyal sistemin güçlülükten yana eğilimin gösterdiğinden söz edebiliriz.

Ancak uygulamalara baktığımızda, bu iyimser tablonun kaybolduğunu görmekteyiz. Çalışanlar, maddi ve manevi ödüllendirmenin yapılmadığı, hoşgörünün gösterilmediği, yenilik ve değişmelerin kolaylıkla kabul görmediği, sıkı bir kontrol altındaki ortamda bulunduklarını algılamaktadırlar. İşbirliği, yardımın ve güvenin olmadığını, yönetim tarafından mesleki gelişim ve sosyal gelişim için desteklenmediklerini, sonuçlardan çok formalitelere önem verildiğini, düşüncelerini açıkça ifade edemediklerini algıladıklarını da belirtmektedirler. Çalışanların hepsi okulun amaçlarını aynı şekilde yorumlamadıklarını ve kendi aralarında bir mesleki yarışmanın olmadığını da, belirtebiliriz. Çalışanların arasındaki çatışmaların uzlaşarak çözümlenmediğini, risk üstlenemediklerini ve öğrenci merkezli bir eğitimin yapılmadığı algıları, bulgularımız arasındadır.

Tüm bu sonuçlardan araştırma evrenimiz olan Çukurova, Gaziantep, Sütçü İmam, Mersin ve Mustafa Kemal BESYO'larında, bulgulanan bazı temel sayıltılarda güçlü bir kültür oluşturabilecek alt yapının varlığına rağmen, uygulamalar açısından algılar, zayıf bir kültür tablosunu ortaya çıkaracak niteliktedir. Bunun nedeni, klasik yönetim anlayışın ve uygulamalarından vazgeçip, çağdaş yönetim anlayışlarının benimsenmemiş olması olabilir.

Z.Serarslan ve arkadaşları (2002) tarafından yapılan "Spor Kuruluşlarında Örgüt Kültürü” adlı çalışmanın sonuçlarına baktığımızda, bizim araştırmamızla benzer sonuçların olduğunu görmekteyiz. Bu araştırma sonucunda şu ifade edilmektedir: "Kişisel değerlerde tüm spor kuruluşlarında "Y Teorisi" ne uygun yönetim anlayışının uygun olduğunu düşündüklerini belirtilmiş ancak, bu teoriye uymayan uygulamaların varlığı saptanmıştır. Bu ise spor kuruluşlarında klasik yönetim uygulamalarının var olduğunu gösterir (22).

Yeni yönetim yaklaşımlarının benimsenmesinde yöneticilerin rolü çok büyüktür. Üst yönetim olmak üzere, diğer tüm yönetim kademeleri, örgütün vizyonunu, inanç ve değerler sistemini örgütsel amaçlara göre şekillendirme ile uygulamaların gerçekleşmesi sorumluluğunu paylaşırlar. Yüksekokullarda, kuruldukların günden buyana görev yapan yöneticilerin uygulamalarda zayıf bir örgüt kültürü tablonun oluşumunda paylarının büyük olduğunu söyleyebiliriz.

Bir örgütün üyeleri, örgütsel uygulamalarda zayıf kültürü ortaya çıkaracak algılamalara sahipse, o örgütte güçlü bir kültürün varlığından söz etmek mümkün değildir.

Sonuç olarak şunu görüyoruz ki, BESYO'ların bazı temel sayıltılar ve uygulamalar açısından algılamaları farklı olmasına karşın, birbirine benzer olarak zayıf bir örgüt kültür örüntüsüne sahiptirler.

Araştırmamızda cinsiyete göre temel sayıltılar ve uygulamalardaki farklı algılamalara baktığımızda, şu maddelerde erkekler ile bayanların algılamalarının farklılaştığını görmekteyiz. Temel sayıltılardan; grup kararlarının daha 
iyi olduğuna, iş'in bir oyun olarak görülmesine, insanların işten hoşlandıklarına ve bu konuda sorumluluk alabileceklerine, insanların güvenilir varlıklar olduğuna, personel arasında yarışın olması gerektiğine erkekler bayanlardan fazla inanmaktadırlar.

Örgütsel uygulamalarda ise, erkekler iş ortamında sıkı bir kontrolün varlığını, herkesin üzerine düşeni yaptıklarını algılarken, bayanlar sonuçlardan çok formalitelere önem verildiğini algılamaktadırlar. Bu farklı algılamaların altında toplumda belirlenen cinsiyet rolleri önem taşır. İnsan doğduğu andan itibaren, toplumsal yaşamda belirlenmiş değerlerle çevrelenir ve yönlendirilir. Yaşamın her alanına ilişkin bu belirlenim, bireyin biyolojik anlamda "dişi" ve "erkek" olmasından bağımsız değildir. "dişi" ve "erkek" oluştan hareketle, iki cinse özgü toplumsal rol dağılımı yapılmakta, toplumsallaşma farklı algılamalarla gerçekleşmektedir. Her iki cinse özgü davranış kalıpları ve değerlerin öğrenilmesi, toplumsallaşmanın önemli boyutunu içerir ve bütünüyle cinsiyetçi mesajlarla yüklüdür. Bayan ve erkeğin toplumdaki görevleri, sorumlulukları, hakları maddi ve manevi şeylerin üretimi sürecindeki konumları, kişilik özellikleri sayılabilen unsur vb. toplumsal cinsiyete göre şekillenir. Bunun sonucunda da bayanlar özel alana, erkekler ise kamusal alana yönlendirilirler. Ülkemizde bayanın üretime katılması, iş yaşamında var olması çok yeni bir süreç olduğu için ve deneyimleri, olayları farklı algılaması, erkeklerle eşit koşullarda yaşamaması durumu, temel sayıltı ve uygulamalardaki farklı algılamaların varlığını doğurmaktadır. Bu durum araştırma bulgularımızda da görülmektedir.

Örgüt kültürü kavramı sosyal antropolojiden alınmasına karşılık, örgüt kuramcıları kültür kavramını sosyal antropologların kültürü tanımlamasından farklı yapmaktadırlar. Sosyal antropologlar kültürü, tüm toplumların bir işlevi ve bir sosyal yapının bütün özelliği olarak ele alırken, örgütsel kültür kavramı, birleştirici, düzenleyici bir mekanizmanın ötesinde yönetim tarafından yaratılan ve yönetilen sosyal bir kontrol aracı olmaya doğru bir gidişi göstermektedir. Bu nedenle, örgüt kültürlerinin amaçlı olarak çeşitli yöntemlerle nasıl değiştirilebileceği, yönetsel amaçlara uygun bir duruma getirileceği ve nasıl güçlendirilebileceği, çağdaş kültür araştırmacılarının üzerinde durdukları konulardır.

Ülkemizde de örgütlerin nasıl bir kültüre sahip olmasının araştırılmasının yanında bu kültürlerin nasıl istendik yönde geliştirilmesi yönünde çalışmalar yapılması BESYO'lar açısından önem taşımaktadır. Örgüt kültürü yaratılmasında, çalışanların neyin önemli olduğunu göstermek ve istendik yönde tutum ve davranışlar geliştirebilmek için bazı yöntemler kullanılır. Eğitim programları, örgüt kültürünün değiştirilmesi veya mevcut kültürün gücünün artırılmasında sık kullanılan bir yöntemdir. Eğitim programlarının temel amacı, çalışanların olası ilgisizliğini kuruma bağlılığa dönüştürerek verimliliği artırmaktır (23). BESYO'larda eğitim programlarının yapılması güçlü kültür oluşturmaya yardımcı olacaktır. Bu eğitim programlarının içeriğinde çok yönlü açık iletişim, liderlik etme, vizyon ve misyonun net tanımlanması ortak sembol ve törenlerin oluşturulması yer almalıdır.

\section{KAYNAKLAR}

1. Berguist, W. H., The Four Cultures of The Academy, Josey-Bass Publishers, San Francisco, 1992.

2. Robbins, S.P., Örgütsel Davranışın Temelleri, Çev. Ayşe Öztürk, Etam A.Ş., 1994.

3. Ramsey R D., Seconday Principal's Survival Guide: Practical Techniques and Materials for Succesful School Administration, New Jersey, Prentice Hall Inc,1992.

4. Bursalığlu Z., Okul Yönetiminde Yeni Yapı ve Davranış, 6. Baskı, A.Ü. Eğitim Fakültesi Yayınları, No:107, Ankara, 1982.

5. Üçışık F., Sporda Sorular ve Çözüm Önerileri, Ötüken Yayınları, İstanbul, 1999.

6. Parsons T., and G.M., Platt, The American University, Mass: Harvard University Press, Cambridge, 1973.

7. Schein E.H., Organizational Culture and Leadership, Jossey Bass., San Francisco, 1985.

8. Plath, D., "Uncovering School Culture: A Case Study of Join Exploration Through Iterrative Interviewing”, Dissertation Abstracts İnternational, 48/8:1953-A, 1987.

9. Kafka K.D., "Organizational Culture in Four Hight School Effectiveness Programs", Dissretation Abstracts International, 50/2, 317-A, 1988.

10. Şişman, M., Örgüt Kültürü, Anadolu Üniversitesi Basımevi, Eskişehir, 1994.

11. Robbins, S.P., Essentials of Organizational Behavior, Prentice-Hall.hmt.Inc, New Jersey, 1988.

12. Harwey, F., and R.Brown R., An Experimental Approach to Organization Development, Prentice-Hall Int:Inc, New Jersey, 1991.

13. Malinowski, B., A Scentific Theory of Culture. Oxford University Press, Oxford, 1948.

14. Lessem, R., Managing Corporate Culture, Vt. Gower, Brookfield, 1990.

15. Hofstede, G., Culture's Conseguences, International Differences in Work Related Values, Sage Publication, London,1980.

16. Handy, Charles B., Understanding Organization (Second Edition) Hazell Watson Ltd., Aylesbury, 1981.

17. Quinn, R., and M. R., McGarth, The Transformation of Organizational Cultures, In P. Forst etal, Organizational Culture, Baverly Hills, Sage, 1985.

18. Kono, T., Corpore Culture and Long-range Planing, Strategic Management in Japanes Companies, Pergaman Press, Oxford, 1992.

19. Hofstede, G., and Others., "Measuring Organizational Cultures: Aqualitative and Quantitative Study Acroos

20. Deal T.E., and A. A. Kennedy, Corporte Culture, Addition-Wesley Publishing, Massachusetts, 1982.

21. Peters, T., and H.R., Waterman, Yönetme Yükselme Sanatı-Mükemmeli Arayış, Çev: Selami Sargut, Altın Kitaplar, İstanbul, 1982.

22. Serarslan, Z., M., Bakır, Ü., Kesim, L., Güler, M.,Yoruç, "Spor Kuruluşlarında Örgüt Kültürü”, Spor Araştırmaları Dergisi, 4/2, s.5570, 2002.

23. Akıncı B.Z., Kurum Kültürü ve Örgütsel İletişim, İletişim Yayınları, İstanbul, 1998. 